\title{
Organisational learning won't be turned off
}

Bente Elkjaer

\section{Introduction}

Enterprises have always been learning organisations in much the same way as it is hard for people to avoid learning. A sign of learning organisations are the many successful enterprises and the abundance of new products and services that keep emerging. The question about organisational learning is, How it is possible to 'see' and to analyse learning when learning is not connected to individuals but to organisations and organising? In a normative sense, however, 'organisational learning' is often used as our answer to the difficulties in enterprises of how most efficiently to channel knowledge to the right people and places in ways that helps to maintain and develop prosperous enterprises. Then, organisational learning is viewed as an image of an enterprise as that of a learning organisation. The guidelines or 'best practices' of how to become a learning organisation are, however, often made with reference to ideas of education, i.e. intentional processes of the production of knowledge. In this paper, I argue that learning and organisational learning does not primarily appear as a result of intended processes, but often as the opposite, i.e. as a struggle to maintain the old and create new.

The field of organisational learning has always reflected the current and contemporary understandings of the management of enterprises. This is the background for providing, first, a brief historical account of the organisational learning literature. I will introduce the most important trends in the literature on organisational learning with the focus upon what is learning, and how are organisations to be understood. The account reflects what may be termed 'cognitive' versions of organisational learning, as well as the 'practice turn' within the social sciences and the humanities. Finally, to complete this history of organisational learning I introduce a pragmatist understanding of organisational learning (Elkjaer, 2003a, 2004; Elkjaer and Simpson, 2011). These different versions of organisational learning draw upon specific understandings of what is learning, and how to conceptualise enterprises as organisations, or rather organising processes, to connote that enterprises are continuously enacted and re-enacted. Following this, the next two sections in the paper deal with the two concepts of learning and organisation/organising. The latter rests upon theories on how to understand the relation between individuals and environments, which is my reason for including a section on just that. I draw the two, learning and organisation, together in a concluding section in which there is also a discussion about how a focus on organisational learning can inspire the research on individual learning. 
Bente Elkjaer

\section{Organisational learning - a brief historical account}

The notion of organisational learning is about 50 years old and it first appeared as an inspiration for making management decisions in enterprises (March and Simon, 1958). The most important work for managers was seen as decision making, and organisational learning was first and foremost driven by management, which at the time was regarded as more or less synonymous with what drove the enterprise as a whole, at least when viewed from the field of management and organisation studies. Management and organisational research had up till then primarily been inspired by economic model thinking, and the theory of the rationally acting 'economic-man' in which decisions are understood to be based upon a fully informed foundation of knowledge. The 'behavioural theory of the firm', however, was gradually making its way into this mainstream understanding of organisations and drove out the idea of abstract modelling in decision theory (Cyert and March, 1963). It became possible to talk about organisational members as not always behaving in an economically rational way, and of decisions as not always made upon all available, but rather a 'satisfied' foundation of, knowledge. The reason put forward was that individuals operate within a cognitive 'bounded rationality', because humans all have a limited capacity for computation of information. There is, in other words, a limit to how much knowledge management can cope with when making decisions. The above notion of organisational learning relies upon a behaviourist understanding of organisations, as opposed to a model thinking thereof, and a definition of learning as individual cognition, because the focus is upon rational processes of the mind.

The notion of organisational learning seemed to rest for some years when making a review of organisational and management studies, but around the mid/late 1970s it popped up again, this time disguised as the idea of an awareness of the importance of open and rational communication processes (Argyris and Schön, 1978, 1996). The point of departure for this understanding of organisational learning was the assumption that humans act upon their cognitive mental models, and that they emerge as defensive when control is about to be lost. In other words, individuals communicate defensively in embarrassing or threatening situations and, furthermore, try to cover up that this is what is done. This results in endless so-called non-productive communication processes that prevent enterprises from learning because of the lack of open validation of assumptions and labelling. An example is that, when somebody asks me why I was so aggressive at the meeting yesterday, I will immediately defend myself, rather than ask why this somebody attributes me as 'aggressive'. I react upon the labelling of my behaviour, instead of asking why this labelling is made. In its aim to develop the concept of non-productive forms of communication in enterprises, the understanding of organisational learning as communication processes draws upon an understanding of organisations as learning systems, and of learning as coming about by creating awareness of these preventive forms of communication in order for organisational learning to flourish.

Both within educational and organisational research as well as within the social sciences as a whole there has been a development, which has been called the 'practice turn' (Schatzki, Cetina, and Savigny, 2001). The idea is to understand, for example, organisations as more than individuals' acting together, but without resorting to an understanding of organisations as systems with a priori defined elements, such as the 'technical' and the 'social' system. Rather, practice is to be understood as continuously performed, and practices are to be understood as 'organised human activities' like, for example, educational practices (Schatzki, 2005). The practice turn within organisational learning moved learning from the inside of individuals' heads to organisational contexts through its understanding of learning as situated. This means, for example, that well-known notions such as motivation for learning should be understood as contextual conditions for motivation, rather than as a result of inner psychic processes. An inspiration for practice-based organisational learning was an understanding of learning as participation in communities of practice in which newcomers move into being old-timers (Lave and Wenger, 1991). When learning in enterprises is viewed as movements from one position to another, it means that it is in this process of participation that one learns to practice a profession and also, through moving, acquires an identity as a competent practitioner. 
The decisive element within a practice-based theory of learning is access to participate and to move in an enterprise defined by its communities of practice.

A practice-based theory of organisational learning was an eye-opener for many scholars, because it (re-) claimed learning as a social, rather than an individual, endeavour (Gherardi, Nicolini, and Odella, 1998). It became possible to see that organisational learning was not just a matter of individuals' learning, but of the organisational patterns of access to participate in some organisational activities and not in others, and the power relations that come with the movements from newcomers to old-timers. Organisational learning could, in other words, be seen as an organisational matter, rather than an individual affair, as previous theories within the field had offered to us (Elkjaer, 2003b).

There are, however, also some questions to be asked to a practice-based theory of organisational learning, namely whether there is a difference between participation and learning, and what it is in the movement from newcomer to old-timer that can be coined as learning and not just socialisation. Another question is whether it is possible to explicate processes of reasoning and not only practising as a part of learning. A third question regards the meaning of agency in an understanding of the enactment of force, rather than attributes of individuals and collectives (like for example organisations); is it, for example, possible to move in an enterprise with more or less commitment, and does this matter for organisational learning (Fenwick and Edwards, 2010)? Finally, if the focus point is induction of newcomers to a field and a profession in order to become part of communities of practice, from where is innovation supposed to come (Fenwick, 2003)? It is possible to find answers to some of these questions in a pragmatist theory of learning and organising, but first some words about the notion of learning.

\section{The notion of learning}

Learning is a term that is used in many fields and contexts as if it was a self-explanatory term. This means that learning is often not explicitly defined, but implicitly implied. In the above, learning can, on the one hand, be analysed as cognitive processes in the mind in order to enhance decision making and to communicate in non-defensive ways. Thus, learning is about computing information and becoming aware of one's defensive ways of communicating. On the other hand, learning in a practice-based version is to be derived from participation in communities of practice, the movements of learners within fields of practices. I find that these two notions of learning may be encompassed by a pragmatist understanding of learning in which action and thinking can never be seen in isolation from each other, but only as partners in all enactments of practice. This needs some further explanation, and the American philosopher and educationalist, John Dewey (1859-1952), helps explain this mutuality between action and thinking.

In his theories of education and learning, Dewey applied ideas from the contemporary theories of functional psychology, in which life and learning are understood as social phenomena (Dewey, 1916 [1980]). This means that the intellect is viewed as a 'function' of social life and that it cannot work in isolation or develop by itself (Dewey, 1896 [1972]). Rather, an intellect develops as an effect of its relations with environments; it is through these continuous encounters that experience is challenged, reshaped and renewed. The sociality of learning and education pervades Dewey's theoretical development thereof, and individuals and environments are, according to Dewey, merely abstractions when viewed in separation from each other. It is meetings with uncertainties that create tensions and frictions; at first these are experienced in an emotional sense and then they may act as input for putting the intellect to work. Thus, when habitual thinking and action are upset, the foundation for having new experience is laid. The difficulties and problems cannot be forced upon anybody from outside, and they can only be solved within the capacity for resolving problems. It is through enquiry into the tensions and frictions that new experience is had, and the potential for new knowledge emerges. The process of knowledge production depends partly on an ability to reflect on the relation between actions and their consequences and partly on the relations that it is possible to establish to previous experience. Some experience may not be apprehended as 


\section{Bente Elkjaer}

knowledge, because it does not enter a conscious and verbal sphere. That does not mean that it is not 'rational', but that knowledge is only one kind of experience, and Dewey was well aware of the ethics and aesthetics of experience and the sensations that this experience provides, at least temporarily. Any delight and comfort in a situation is also an experience, and there is little distinction between a knowing intellect and an acting body. Thus, along the continuum of experience, there is a vague transfer between bodily and cognitive experience. In other words, a comprehensive understanding of Dewey's theory of learning encompasses an anti-dualist relation between being and knowing, action and thinking.

To fully understand the value of Dewey's pragmatism for learning, it is important to remember that it is not the individual or the environment that is the point of departure, but the aspects of a situation in which subjects, objects, action and agency all are a part. The uncertain situation is open to enquiry in the sense that its constituting elements are experienced as unconnected. Dewey describes enquiry as a process that starts with a sense that something is wrong; a problem is felt. The suspicion does not present itself as cognitive until the enquirer(s) begin(s) to define and formulate the problem, and the human ability to reason and think verbally is activated. Enquirers use previous experience from similar situations and try to solve the problem by applying different working hypotheses. The initial sense of tension and friction must be replaced by a sense of consummation before the problem has been resolved. If the enquiry is to lead to learning and new knowledge, it requires thoughts on the relation between the anticipated problem and hypotheses and the resolution of the problem.

Going back to both a cognitive and a practice-based understanding of learning, I think that Dewey's pragmatism helps to see that participation holds potentials for both socialisation and learning. Learning is the result of participation when reasoning (thinking, cognition) is not only reflecting back on the past, but also includes anticipatory thinking of an unknown future in playful and experimental ways (Elkjaer, 2009). This means that it is also possible to learn through experimenting with different theories and concepts as 'instruments' and 'tools to think with' without going into the cognitive mode of learning, but maintaining the importance of the connection between action and thinking. Further, it is in bringing our attention to the value of reasoning as an aspect of complex situations by the use not only of concepts and theories but also of body and emotion that pragmatism transcends and encompasses a cognitive and a practice-based understanding of learning. Pragmatism does not only emphasise retrospective re-flection to understand past phenomena, but is also critically anticipating the consequences of decisions and choices. This is what makes a pragmatist-inspired theory of learning into a tool for a visionary and innovative development of work as well as the organisation and management thereof. This is elaborated in a pragmatist understanding of organisation and organising, but first some words on theories of the relations between individuals and environments, because this is what makes much turmoil in the field of organisational learning and the practices of learning organisations: How to get from one to the other and vice versa?

\section{Relations between individuals and environments}

When the learning subject is an organisation, it is important to address the relation between individuals and environments, or subjects and worlds, as I prefer to call them, to connote the interpretive, as opposed to the essentialist, understandings of the two (see also Lave, 1997). Altman and Rogoff (1987) coin four different ways to understand the subject-world relationship, namely as (1) traits or attributes, (2) interactional, (3) organismic or systemic, and (4) transactional. They take their point of departure in Dewey and Bentley's concepts of how humans change and become knowledgeable about their environment (1949 [1991]). Dewey and Bentley differentiate between the following three understandings thereof and term them, 'self-action', 'inter-action' and 'trans-action':

Self-action: where things are viewed as acting under their own powers. Inter-action: where thing is balanced against thing in causal interconnection. Trans-action: where systems of description and 
naming are employed to deal with aspects and phases of action, without final attribution to 'elements' or other presumptively detachable or independent 'entities', or 'realities', and without isolation of presumptively detachable 'relations' from such detachable 'elements'.

(Dewey and Bentley, 1949 [1991]: 101-2).

When the relation between subject and world is understood on the basis of an understanding of the two as separated, self-acting entities, the assumption is that the function of physical and social phenomena is governed by an inner self, internal essences, self-powers, forces, or intrinsic qualities inherent in these phenomena. It is the inner and stable traits of subjects and worlds that determine their function, which means that physical and mental phenomena are defined and operate more or less independently of each other and of their contexts. An example of organisational learning within this understanding of the relation between subjects and worlds may be to view individuals' ability for decision making as organisational learning.

When the relation between subjects and worlds is defined as inter-action, it refers to the fact that physical and mental elements exist independently of each other and possess specific properties. These elements can, however, interact on the basis of specific regularities or principles and in that way influence each other. Time and space can be included in the interaction, but are normally treated as variables in the study of phenomena. Organisational learning as communication processes fits well into this understanding, because of its foundation in the causal relations between individuals' patterns of communication and productive organisational learning systems.

When subjects and worlds are related to each other on the basis of a transactional understanding thereof, time and space are inseparable. Time and space, history and context, are, in the transactional understanding of the relation between subjects and worlds, aspects of an integrated unity, a situation. Practice-based organisational learning can be understood within this understanding of the relation between subjects and worlds. A pragmatist version of organisational learning, with its explicit focus upon the study of learning as aspects of uncertain situations in which there is a struggle to resolve the tensions and frictions that the uncertainty may cause, rests, however, more clearly upon this understanding of subjects and worlds.

In a transactional understanding of the relation between subjects and worlds, the unit of analysis is not either one or the other, but aspects of a situation or an event. The situation is contextual and unfolds over time, and it is a unity of intertwined and complex phenomena whose parts are mutually penetrating and inseparable. Thus, a social situation can only be studied as a united whole (Brandi, 2010). One cannot first tear a situation apart and then study its elements to understand the whole, because a social whole cannot be reduced to the sum of its parts. In contrast to a systemic understanding of this relation between subjects and worlds, the transactional understanding of this relation allows for the study of unique situations and events without necessarily referring to them as part of larger predefined elements of a system. This, however, does not mean that one cannot find a pattern or order, only that the point of departure for (de-)constructing the whole is the situation or event, not the other way around.

The understanding of the relation between subjects and worlds on the basis of a transactional understanding is helpful in conceiving of the organisation/organising embracing both persons and the institutional order that makes up the organisation (Holland and Lave, 2001). When you subscribe to a transactional understanding of the relation between subjects and worlds, it means that the unit of analysis is the situation or the event in which subjects act and think with the institutional order, and not in it. Studying organisational learning means studying the patterns of organisational commitments to organisational situations or events as combined actions and thinking, and enquiring into the tensions and frictions that arise from the differences in commitments. This is elaborated below when organisations and processes of organising are understood as arenas of social worlds. 
Bente Elkjaer

\section{The notion of organisation/organising}

In much the same way that learning cannot be reduced to issues of knowledge, because emotion, aesthetics and ethics are also a part, organisational learning is much more than processes of knowledge. The organisational dynamics are comprised by a mixture of structures and cultures, politics and power, emotions, aesthetics and ethics and probably more. The crucial point is that it is not possible to reduce organisations to just people, because it is not only people but also the organisational features of these people that are at play, e.g. managers, IT specialists, nurses, case-workers, etc. The features carry a field of practice and identities that are subjectively formed, but also intertwined with the ascribed meaning to and position of the feature. This means that organisational learning cannot be reduced to individuals' learning in organisations, although this is also present, but, in order to fully understand organisational learning, we need to define organisational learning as specific cultural and historical practices of enacting organisation within enterprises (see also Usher and Edwards, 2007). In other words, when the learning subject is an enterprise, it is necessary to define what an organisation is, and which cultural and historical practices of organising may be termed learning.

Organisations have been coined as learning subjects in a number of ways, for example, and as previously mentioned, as learning systems in which individuals are learning on behalf of the system (Argyris and Schön, 1996). Other ways have been to coin organisations as forms of collectives involving not only humans, but also divisions of labour, processes of mediation and artefacts like activity systems (Engeström, 2001), actor networks (Fox, 2000), or, as mentioned above, communities of practice (Lave and Wenger, 1991). I prefer to work with a pragmatist-inspired understanding of organisations as arenas of social worlds.

Dewey is helpful in defining a concept of learning in which it is the tensions and frictions that an uncertain situation may create and which, in turn, may trigger enquiry and possibly learning, not only by subjects, but also in ways that may change situations and the social worlds of which they are a part. Dewey's theories of learning provide us with an understanding of how subjects learn and of how situations and events unfold and change, but what is missing is some conceptual elaboration on how to coin the context of work, its organisation and management. The American sociologist Anselm Strauss's understanding of organisations as arenas of social worlds made up by commitments to workplace practices is, I think, a good way to ascribe learning neither to systems nor to subjects, but to situations, work and the organising processes of enterprises.

Strauss gets his inspiration from pragmatism, especially in Dewey's social-psychological work, Human Nature and Conduct (1922 [1988]) and from symbolic interactionism, which is the sociological variant of the Chicago-school (Fisher and Strauss, 1978). Strauss applied the notion of 'interaction', but the meaning thereof is the same as Dewey's term 'transaction' (Clarke, 1991; Strauss, 1978, 1993). Strauss's theory about the organising of work and of workplaces is focussed upon action and interaction as continuous processes. The foundation for Strauss's work is that the world is highly complex and that social stability and social change are two sides of the same coin. This is why process and structure or structuring, which is Strauss' preferred concept, continuously constitute each other, but in a non-deterministic way.

Strauss' understanding of organisations as arenas made up by social worlds takes its point of departure in work defined as 'coordinated, collective actions'. An organisation is, according to Strauss, the organising of collective, coordinated actions around work. The organisation is an arena, which indicates that the boundaries of the organisation are open to other social (and natural) worlds. In other words, an organisation does not have walls that are determinant of the organisational activities. These are determined by the commitments to collective actions, their trajectories and the contextual conditions with which they are played out. It is within the arena (an open space) that the organisational practice unfolds and organises into social worlds, which are defined as follows:

Groups with shared commitments to certain activities, sharing resources of many kinds to achieve their goals, and building shared ideologies about how to go about their business.

(Clarke, 1991: 131; quoted in Strauss, 1993: 212) 
In this definition, we find people, but in the shape of organisational members with certain commitments or obligations to the organisational practices, and not just individuals with their own agendas. Organisational members' features are played out in their commitments, but commitments are at the same time personal. 'Social worlds' is a concept for an empirical understanding of the organising practices of work in an enterprise. This is Strauss's attempt to get away from the idea of a priori determined social structures like class, ethnicity, gender, employees, management, etc. as the determinant and decisive variables for work and life in an organisation. Strauss defines structures as the longer (in time) lasting conditions for organisational action. Structures are then taken for granted by the actors, even if they are not always visible for them, but they can, nevertheless, be read into the commitments to the organisational social worlds and social practices. Structures contain both a social-psychological (personal) aspect by the term commitment, and make up the more encompassing social organising of work and enterprises by way of the acting out of the features of the organisational members.

The notion of (trans-)action as the central turning point for participation in a social world is specifically pragmatist. The empirical question here is, Who cares and what do they want to do about it? The transactions are empirically and concretely defined and they can encompass many different forms like negotiations, ways of collaboration, tensions and frictions. The meanings of these transactions can be understood through an understanding of the commitments displayed by organisational members. Organisations as arenas made up by social worlds is an understanding that is open towards participation, structures and processes and this separates it from a priori understandings of organisations as systems. It is an understanding that is based upon organisational theory that seeks to understand and conceptualise the complexity of social organising rather than dismiss it (Clarke, 1991). The theory provides a conceptual understanding for analysing both the range of organisational forms and phenomena and the different and diverse social processes taking place within and among them.

\section{Conclusion and discussion}

I began this paper by claiming that all organisations are learning, just as individuals are. The issue, however, is how learning unfolds when it is connected to organisations and organising rather than individuals. Organisational learning will, as a concept derived from management and organisation studies, always reflect contemporary issues and problems for the management of enterprises. This was my reason for providing a historical account of the field of organisational learning in which organisational learning was first seen as an answer to management decision processes, and later as a means to create less-defensive communication processes in enterprises in order to make enterprises learn. These two versions of organisational learning both rest upon an understanding of learning as cognition, and of enterprises as (learning) systems.

The practice turn brought new definitions of learning and of organising into the field of organisational learning, because organisational learning was now seen as being derived from the movement from newcomers to old-timers brought about through access to participate in the communities of practice of an enterprise. Many scholars have been inspired by this version of organisational learning, but I have raised the issue of the disappearance of reasoning in learning; the importance of different commitments to work and enterprise; and the tensions and frictions following from that, which, however, through enquiry may hold possibilities for learning and, in turn, new creative and innovative practices in enterprises.

These issues led me to define organisational learning as aspects of certain cultural and historical practices within enterprises and to elaborate on the relation between subjects and worlds as important for understanding organisations and organising. The result of this was a proposal of a transactional relationship between subject and institutionalised order. This may be contained within a pragmatist notion of the situation or event in which learning, with its emphasis on experience and enquiry, may arise out of emotional uncertainty. Thus, a pragmatist understanding of organisational learning rests upon an understanding of organisations as arenas of social worlds made up by different commitments to organisational practices. 


\section{Bente Elkjaer}

These different commitments may create situations of uncertainties leading to tensions, which, in turn, may lead to organisational development and learning, resulting in the reorganisation of organisational work and life.

The question to be answered is how the field of organisational learning can contribute to our knowledge of individual learning. First of all, I think that a focus upon organisational learning makes it possible to separate learning from education, i.e. from learning as an intentional endeavour often guided by somebody other than the learner. Although much literature on organisational learning, and in particular its allied research field, workplace learning, deals with some forms of educational elements like mentoring and coaching, and other forms of education, the main tenets of organisational learning are that learning derives from the organisation of work and workplace practices (see e.g. Billett, 1999). This reminds us that learning at school is not necessarily related to lessons and teachers, but to the organising of schooling and students.

Second, the inspiration from organisational learning makes it possible to discuss the educational system as an arena for learning, i.e. as an arena in which power, inclusion and exclusion can be viewed differently through seeing educational institutions as organisations and organisers of learning, rather than being a result of attributing traits to individuals. Third, a focus upon organisational learning provides an occasion to rethink the relation between subjects and worlds as a complex and meaningful relation that also includes (but does not determine) the ascribed meaning to features of members and contexts such as managements and employees. This takes the focus away from individuals' motivation for learning and to the contextual conditions for motivation and learning. Finally, for educational professionals like teachers, management and even researchers within the field of learning and education, I think that a focus upon organisational learning may help pave the way for encompassing not only didactics of learning in a narrow way, but also the importance for learning of including organising processes of learning and education as part of organising learning connected to educational institutions.

\section{References}

Altman, I. and Rogoff, B. (1987). World Views in Psychology: Trait, Interactional, Organismic, and Transactional Perspectives. In D. Stokols and I. Altman (Eds), Handbook of Environmental Psychology (Vol. 1, pp. 7-40). New York: John Wiley and Sons.

Argyris, C. and Schön, D. A. (1978). Organizational Learning: A Theory of Action Perspective. Reading: Addison-Wesley Publishing Company. (1996). Organizational Learning II. Theory, Method, and Practice. Reading: Addison-Wesley Publishing Company.

Billett, S. (1999). Guided Learning in Work. In D. Boud and J. Garrick (Eds), Understanding Learning at Work (pp. 151-64). London: Routledge.

Brandi, U. (2010). Bringing Back Inquiry - Organizational Learning The Deweyan Way. In S. Jordan and H. Mitterhoffer (Eds), Beyond Knowledge Management - Sociomaterial and Sociocultural Perspectives within Management Research (pp. 95-121). Innsbruck: Innsbruck University Press.

Clarke, A. E. (1991). Social Worlds/Arenas Theory as Organizational Theory. In D. R. Maines (Ed.), Social Organization and Social Process. Essays in the Honor of Anselm Strauss (pp. 119-58). New York: Aldine de Gruyter.

Cyert, R. M. and March, J. G. (1963). A Behavioral Theory of the Firm. Englewoods Cliffs, NJ: Prentice-Hall.

Dewey, J. (1896 [1972]). The Reflex Arc Concept in Psychology. In J. A. Boydston (Ed.), Early Works 5 (pp. 96-109). Carbondale and Edwardsville: Southern Illinois University Press.

(1916 [1980]). Democracy and Education. An Introduction to the Philosophy of Education. In J. A. Boydston (Ed.), Middle Works 9. Carbondale and Edwardsville: Southern Illinois University Press.

(1922 [1988]). Human Nature and Conduct. In J. A. Boydston (Ed.), Middle Works 14. Carbondale and Edwardsville: Southern Illinois University Press.

Dewey, J., and Bentley, A. F. (1949 [1991]). Knowing and the Known. In J. A. Boydston (Ed.), Later Works 16 (pp. 1-294). Carbondale and Edwardsville: Southern Illinois University Press.

Elkjaer, B. (2003a). Organizational Learning with a Pragmatic Slant. International Journal of Lifelong Education, 22(5), 481-94. 
(2003b). Social Learning Theory: Learning as Participation in Social Processes. In M. Easterby-Smith and M. Lyles (Eds), The Blackwell Handbook of Organizational Learning and Knowledge Management (pp. 38-53). Malden, Oxford, Melbourne, Berlin: Blackwell Publishing.

-(2004). Organizational Learning: The 'Third Way'. Management Learning, 35(4), 419-34.

- (2009). Pragmatism. A Learning Theory for the Future. In K. Illeris (Ed.), Contemporary Theories of Learning. Learning Theorists ... In Their Own Words (pp. 74-89). Abingdon, New York: Routledge.

Elkjaer, B., and Simpson, B. (2011). Pragmatism: A Lived and Living Philosophy. What Can It Offer to Contemporary Organization Theory? Research in the Sociology of Organizations.

Engeström, Y. (2001). Expansive Learning at Work: Toward an Activity Theoretical Reconceptualization. Journal of Education and Work, 14(1), 133-56.

Fenwick, T. (2003). Innovation: Examining Workplace Learning in New Enterprises. Journal of Workplace Learning, 15(3), 123-32.

Fenwick, T., and Edwards, R. (2010). Actor-Network Theory in Education. London and New York: Routledge. Taylor and Francis Group.

Fisher, B., and Strauss, A. L. (1978). The Chicago Tradition and Social Change: Thomas, Park And Their Successors. Symbolic Interaction, 1(2), 5-23.

Fox, S. (2000). Communities of Practice, Foucault and Actor-Network Theory. Journal of Management Studies, 37(6), 853-67.

Gherardi, S., Nicolini, D., and Odella, F. (1998). Toward a Social Understanding of How People Learn in Organizations. The Notion of Situated Curriculum. Management Learning, 29(3), 273-97.

Holland, D., and Lave, J. (2001). History in Person: An Introduction. In D. Holland and J. Lave (Eds), History in person. Enduring Struggles, Contentious Practice, Intimate Identities (pp. 3-33). Santa Fe and Oxford: School of American Research Press and James Currey.

Lave, J. (1997). Learning, Apprenticeship, Social Practice. Nordisk Pedagogik, 17(3), 140-51.

Lave, J., and Wenger, E. (1991). Situated Learning. Legitimate Peripheral Participation. Cambridge: Cambridge University Press.

March, J., and Simon, H. A. (1958). Organizations. New York: Wiley.

Schatzki, T. R. (2005). The Sites of Organizations. Organization Studies, 26(3), 465-84.

Schatzki, T. R., Cetina, K. K., and Savigny, E. V. (Eds). (2001). The Practice Turn in Contemporary Theory. London and New York: Routledge.

Strauss, A. L. (1978). A Social World Perspective. Studies in Symbolic Interaction, 1, 119-28.

(1993). Continual Permutations of Action. New York: Aldine de Gruyter.

Usher, R., and Edwards, R. (2007). Lifelong Learning - Signs, Discourses, Practices. Dordrecht, The Netherlands: Springer. 